\title{
Teknokultura
}

ISSNe: 1549-2230

http://dx.doi.org/10.5209/TEKN.59568

\section{Wombastic, la batalla gráfica por la reapropiación del cuerpo femenino frente a la amenaza antiabortista de Gallardón}

\author{
María Márquez López ${ }^{1}$
}

Recibido: 28 de marzo de 2018 / Revisado: 19 de junio de 2018 / Revisado: 24 de agosto de 2018 / Aceptado:. 5 de septiembre de 2018 Open peer reviews

Resumen. El proyecto antiabortista que el Gobierno del Partido Popular desarrolló entre 2010 y 2014 provocó una reacción social de calado en nuestro país, al entenderse que la custodia legal-médica que pretendía sobre el cuerpo de la mujer suponía un claro retroceso en sus derechos. Al vulnerar la dignidad y la libertad de la población femenina, esta ley se convertía en una forma de violencia de género. Entre las diversas iniciativas surgidas en ese periodo se encuentra Wombastic, la plataforma gráfica en Tumblr creada por la Asociación de Autoras de Cómic, donde la reivindicación del cuerpo femenino, como territorio vetado a decisiones externas a la propia mujer, se tradujo en más de 250 imágenes y eslóganes aportados por ilustradoras y autoras de cómic entre febrero y septiembre de 2014, fecha esta última en la que dimitió el por entonces ministro de Justicia y encargado de defender el proyecto legislativo, Alberto Ruiz-Gallardón. Las creaciones eran de libre descarga, con el objetivo de inundar las calles y las manifestaciones de estos carteles de protesta. Mujeres reapropiándose de sus cuerpos ante la amenaza de la tutela estatal, dibujadas con tintes humorísticos y/o solemnes, pero siempre rotundas en sus mensajes, y un ex ministro Gallardón ridiculizado, fueron los denominadores comunes.

Palabras clave: aborto; artistas; cuerpo; ley; mujeres.

\section{[en] Wombastic, the graphic battle for the reappropriation of the female body in the face of Gallardón's anti-abortion threat}

\begin{abstract}
The pro-life project that the Government of the Partido Popular developed between 2010 and 2014 caused a important social reaction in our country, understanding that the legal-medical custody that pretended on the woman's body supposed a clear regression in her rights. By violating the dignity and freedom of the female population, this law became a form of gender violence. Among initiatives that emerged in that period, Wombastic, the graphic platform on Tumblr created by the Asociación de Autoras de Cómic, where the vindication of the female body, as territory forbidden to external decisions to the own woman, was translated in more than 250 images and slogans contributed by illustrators and authors of comic. The creations were free download, with the aim of flooding the streets and demonstrations of these protest posters. Women reappropriating their bodies in the face of the threat of state tutelage, drawn with humorous and/or solemn intentions, but always resounding in their messages, and a ridiculed minister Gallardón, were the common denominators.
\end{abstract}

Key words: abortion; artists; body; law; women.

Sumario. 1. Introducción. 2. La gestante no importa. 3. Los vigías (históricos) de la maternidad. 4. Obligadas a reconquistar el derecho a decidir. 5. Referencias.

1 Universidad Rey Juan Carlos de Madrid (España)

e-mail: mj.marquez1.2016@alumnos.urjc.es 
Cómo citar: Márquez López, M. (2018). Wombastic, la batalla gráfica por la reapropiación del cuerpo femenino frente a la amenaza antiabortista de Gallardón, en Teknokultura 15(2), 275-284.

\section{Introducción}

El Partido Popular desarrolló durante la campaña electoral de 2010, previa a su regreso al Gobierno tras la etapa socialista (noviembre de 2011), el Anteproyecto de ley orgánica para la protección de la vida del concebido y de los derechos de mujer embarazada, con el objetivo de reformular la norma que el Ejecutivo de Zapatero había aprobado en julio de 2010, la Ley de Salud Sexual y Reproductiva $y$ de la Interrupción Voluntaria del Embarazo. Pese a que el último Consejo de Ministros de 2013, presidido por Soraya Sáenz de Santamaría, aprobó el texto, el clamor de una parte notable de la sociedad española y el impacto negativo que tuvo en el electorado moderado popular (reflejado en el descenso de voto en las elecciones europeas), desembocó en la retirada del proyecto y la dimisión del ministro encargado de defenderlo, el titular de Justicia, Alberto Ruiz-Gallardón (Cué, 2014).

El rechazo de las mujeres españolas al objetivo legislativo popular se canalizó en una gran movilización denominada El Tren de la Libertad, que recorrió las calles de Madrid el 1 de febrero de 2014, si bien en los tres años en los que el Gobierno perfilaba el texto, tuvieron lugar numerosas muestras de indignación feminista, entre ellas, la plataforma creada en Tumblr por la Asociación de Autoras de Cómic (AC), Wombastic (Wombastic, 2014), que se convirtió en un campo de batalla gráfico. Wombastic tuvo además una traslación al papel por parte de la revista Píkara (año 3) mediante una selección de algunas aportaciones, y el eco de la iniciativa llegó también a la prensa nacional (Olías, 2014).

Wombastic (womb es útero en inglés) se convirtió durante semanas en un contenedor de alegatos gráficos rotundos, liberadores, con decenas de dibujos de mujeres empoderadas frente a un ex ministro Gallardón caricaturizado. Según la AC, la plataforma recibió más de 250 imágenes entre febrero y septiembre de 2014, cuando se dio por finalizada la campaña tras la retirada de la norma y la dimisión del titular de Justicia. En este artículo aparecen tres de esas imágenes.

La ley que el Gobierno pretendió instaurar reducía la despenalización del aborto a dos únicos supuestos: la violación (12 semanas como plazo límite para la intervención); y el peligro para la vida/salud física o psíquica de la mujer (22 semanas). Es decir, desaparecía la anomalía fetal como supuesto, contraviniendo la protección de los derechos de las mujeres recogida en diversas directrices internacionales, como por ejemplo el Comité de Derechos Humanos de la Organización de Naciones Unidas. Por otro lado, convertía a los médicos en los tutores de la decisión de la afectada para calibrar el citado riesgo fetal. Otro de los puntos que tenía pendiente el gobierno de Rajoy era responder a la reformulación socialista de la ley de 1985, no solo por las 14 semanas para practicar el aborto libre, sino también para volver a exigir el consentimiento paterno para las menores de 16 y 17 años.

La pretensión del Partido Popular eliminaba la libertad de las mujeres para decidir por qué y cuándo podían interrumpir sus embarazos. Volvería la tutela legal y 
médica sobre sus vidas que había contemplado la Ley Orgánica 9/1985, pues con la norma presocialista se requería de un informe que validase el cumplimiento de los tres supuestos despenalizados por entonces (terapéutico, criminológico y eugenésico). Los criterios biológicos que históricamente han aducido legisladores y médicos para intervenir en la decisión de las mujeres sobre la maternidad, camuflan distinciones de su grupo social con respecto al de los hombres, por razones de género. Este ánimo legislador "forcing women to asume a role and to perform work that has long been used to subordinate them as a class" (Siegel, 1975, p. 65). La reproducción como fin último de la población femenina entronca además con postulados religiosos que, en la tentativa de reforma en nuestro país quedaron ampliamente al descubierto, como ha ocurrido históricamente cuando las mujeres han tomado el control de la reproducción.

La vulneración de derechos humanos fundamentales y la sublimación de la maternidad por encima de otras facetas vitales son síntomas de una violencia estructural legitimada por el patriarcado que, como sistema de dominación social, ubica a las mujeres en la categoría de "inferiores y propiedad de los varones, a los que deben respeto y obediencia" (De Miguel, 2015, p. 253). De esta forma, el Estado/ministro/legislador canaliza su violencia mediante la potestad legislativa reforzando la desigualdad entre hombres y mujeres. Tutores de la reproducción humana y tuteladas. Históricamente los discursos religiosos, muy evidentes en el respaldo al proyecto normativo que nos ocupa, han sido también un pilar fundamental para validar la desigualdad sexual al polarizar a la mujer como "mala y peligrosa" o "tentación, la ocasión para pecar" (De Miguel, 2015, p. 253) o madre.

Si la ley de Gallardón hubiese prosperado, España se habría convertido en uno de los países europeos con la legislación más restrictiva en este asunto. No hay que olvidar además que su proyecto entraba en contradicción con varias directrices legislativas y protocolarias tomadas para sensibilizar y prevenir contra la violencia de género ( $\mathrm{VdG}$ ) a escala internacional y nacional. En términos conceptuales, contradecía a la Ley Orgánica 1/2004, de 28 de diciembre, de Medidas de Protección Integral contra la Violencia de Género, aprobada por mayoría absoluta en el Congreso (Nogueira, 2004), y en cuya exposición de motivos se refiere que las agredidas lo son "por el hecho mismo de ser mujeres", convirtiéndose en sujetos "carentes de derechos mínimos de libertad, respeto y capacidad de decisión". A la reflexión sobre cómo dicho proyecto normativo efectivamente vulneraría la libertad en un plano físico-corporal, habría que añadir el plano psicológico, entendiendo como violencia de este tipo "la conducta que atenta contra la integridad psíquica y emocional de la mujer y contra su dignidad como persona", definida así en el Protocolo común para la actuación sanitaria ante la Violencia de Género (Ministerio de Sanidad, Servicios Sociales e Igualdad, 2012). En esta última definición, se vincula la perpetración de esta violencia a "la pareja" que "impone" las "pautas de comportamiento" que él considera que ella debe asumir. El problema es que si ampliamos la categoría del sujeto agresor, del hombre al Estado, nos encontramos que en nuestro país no existe una definición de violencia institucional, ni en la Ley 1/2004 ni en normas autonómicas (Bodelón, 2014, p. 135). En la legislación mexicana (Ley General de acceso de las mujeres a una vida libre de violencia, 2007, artículo 18) aparece como "actos u omisiones de servidores públicos que discriminen o tengan como fin dilatar, obs- 
taculizar o impedir el goce y ejercicio de los derechos humanos de las mujeres" (Bodelón, 2014, p. 133). ¿Cómo concebir entonces que legisladores y médicos decidan sobre el cuerpo femenino hasta llegar a ponerlo en riesgo al suprimir el supuesto de la malformación fetal?

El abordaje de la violencia de género desde la óptica de los derechos humanos se consideró por primera vez en la Conferencia Mundial de Derechos Humanos organizada por la Asamblea General de las Naciones Unidas en 1993. La Declaración sobre la eliminación de la violencia contra la mujer (ONU, 1993), aprobada en este marco, alerta sobre la posibilidad de que también el Estado ejecute o tolere violencia "física, sexual y psicológica" sobre la mujer "donde quiera que ocurra" (artículo 2, apartado c). Un año más tarde, la Conferencia Internacional sobre Población y Desarrollo (ONU) explicitaba los vínculos entre la VdG, la salud y los derechos reproductivos de las mujeres. La IV Conferencia Mundial de Mujeres, celebrada en Beijing en 1995, supuso un hito en la medida en la que amplió conceptualmente qué puede ser considerado $\mathrm{VdG}$ y, sobre todo, por haber enmarcado el origen de la misma como la "manifestación de las relaciones de poder históricamente desiguales entre mujeres y hombres, que ha conducido a la dominación masculina, a la discriminación y a impedir el pleno desarrollo de la mujer" (ONU, 1993). En el ámbito europeo, el Comité de Ministros del Consejo de Europa aprobó una importante recomendación en 2002 sobre Protección de la Violencia contra la Mujer en la que, además de diferenciar violencia doméstica y de género, recogía el planteamiento de la ONU señalando al Estado "o sus oficiales" como posibles consentidores o ejecutores de VdG. Por último, en 2006 fue publicado por la ONU el primer análisis internacional sobre este problema social bajo el título Estudio a fondo sobre todas las formas de violencia contra la mujer (ONU, 2006), en el que se detallaron todavía más tres claves fundamentales: a) cómo el Estado puede ejercer la $\mathrm{VdG}$, "por conducto de sus agentes o mediante políticas públicas"; b) de qué representantes estatales estaríamos hablando, "miembros de los poderes legislativo, ejecutivo y judicial, agentes de la ley, funcionarios..."; c) las "leyes y políticas" pueden ser el canal para cometer violencia contra la mujer.

Las tres ilustraciones que se muestran a continuación inciden en las claves de la vulneración de derechos que pretendía el ex ministro Gallardón. La aspiración política de interferir en los derechos reproductivos tenía una segunda lectura perversa, la de reducir a la mujer a su papel de madre. Poner el foco en el nasciturus y el cuidado de este por encima de la propia salud de la madre, limitada a "incubadora con patas", como denuncia la ilustradora Cinta Villalobos (imagen 1). La perpetuación de este estereotipo de género por parte del Estado mediante una ley supone una "institucionalización" del mismo, "le provee de un marco legal para facilitar la perpetuación de la discriminación en el tiempo y a través de diferentes sectores de la vida y las experiencias sociales" (Cook en Bodelón, 2014, p. 141). En este sentido, el papel de la Iglesia como instigadora del retroceso que el proyecto supondría para los derechos reproductivos de las españolas fue crucial, como denuncia Joanna Nieto (imagen 2). Por último, el derecho a decidir, el atentado contra la autonomía y libertad de una persona, se refleja en la aportación de Nuria Tamarit (imagen 3). 
Figura 1. Autora: Cinta Villalobos. Fuente: Wombastic.

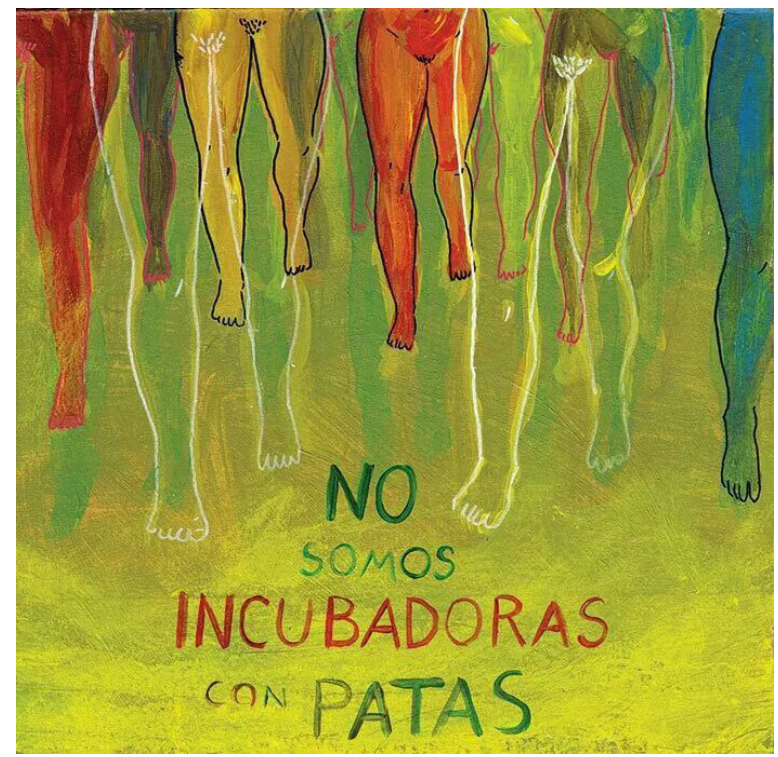

\section{La gestante no importa}

El proyecto antiabortista liderado por el ex ministro Gallardón colocó a la maternidad en el centro del debate público entre 2009 y 2014. La voluntad del gobierno de Mariano Rajoy fue apoyada abiertamente por la Iglesia, grupos pro-vida y el Opus Dei, institución esta última a la que pertenecen varios nombres importantes del PP que habían impulsado la reforma legislativa en este ámbito (Cué, 2014). El término "nasciturus" ocupó páginas de periódicos y debates mientras que la figura de la mujer quedaba relegada a un segundo plano, presentada como totalmente alienada con respecto a la gestación, que no parecía "pertenecerle", en palabras de Young, sino que pasaba por ser formulada como "a state of the developing fetus, for which the woman is a container" (Young, 2005, p. 46). En términos antiabortistas, el embarazo se corresponde con lo que la politóloga norteamericana describe como "or an objective, observable process coming under scientific scrutiny, or it becomes objectified by the woman herself as a condition in which she must take care of herself" (Young, 2005, p. 46). En la presentación del proyecto de la norma en rueda de prensa, el ex ministro de Justicia lo dejó claro: "No cabe depender de la exclusiva voluntad de la mujer embarazada" (García y Elorduy, 2013). La intención del Gobierno era dejar sin voz a la gestante, quien pasaría a depender exclusivamente de la tutela médica. El Estado la incapacitaría así para tomar una decisión sobre su cuerpo y su futuro, reduciéndola al "container" que menciona Young o incubadora del nasciturus, como denunció en Wombastic la ilustradora Cinta Villalobos, con el lema "No somos incubadoras con patas" (imagen 1). Villalobos dibuja a mujeres reducidas a vaginas y piernas (según el postulado de la 
reforma legislativa popular), en una imagen en la que el rojo sangre se alterna con el verde esperanza del grito feminista que denuncia y con el trazo fantasmagórico de la tiza, evocando la incertidumbre vital de la mujer que hubiese sido obligada a gestar durante nueve meses una anomalía fetal. Y pese al desasosiego de ver cómo pueden ser vulnerados sus derechos, caminan juntas en la protesta, basan su fuerza en la sororidad, como ocurría treinta años antes.

Figura 2. Autora: Joanna Nieto. Fuente: Wombastic.

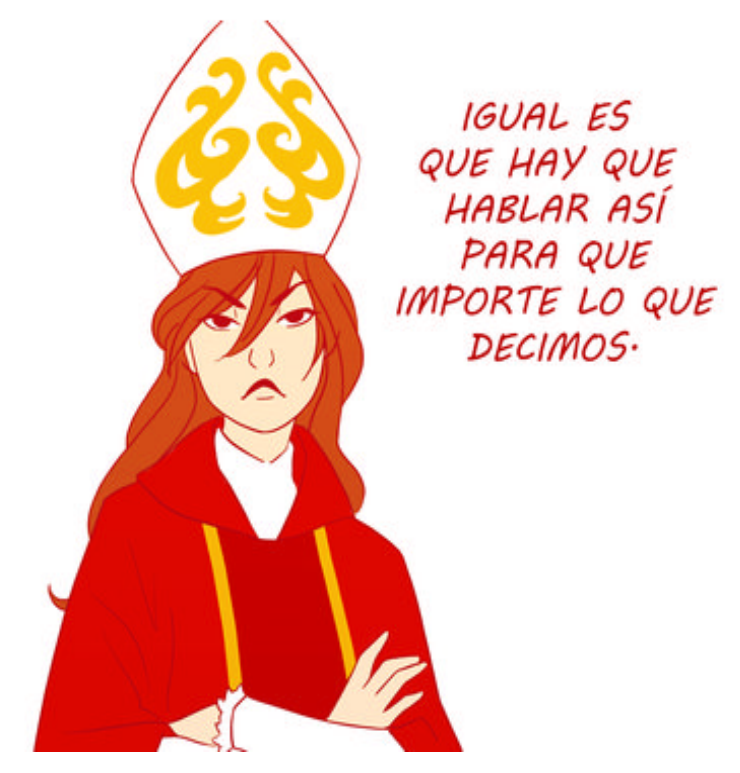

\section{Los vigías (históricos) de la maternidad}

La representación simbólica de la mujer como "productora de cuerpos" fundamenta el discurso patriarcal remarcando la distancia de esta con respecto al hombre, polarizando la esfera pública, donde habitan ellos como "los iguales, individuos-ciudadanos", de la privada donde se encuentran ellas como "las idénticas, madres-esposas" (De Miguel, 2015, p. 233). Legisladores, comunidad médica e Iglesia se han erigido históricamente como vigías de la reproducción humana, sometiendo a las mujeres en función de sus privilegios de clase. A partir del siglo XIV, que las féminas controlasen la reproducción comenzó a verse "como una amenaza a la estabilidad económica y social" tras los estragos de la Peste Negra, lo que acabaría desembocando en la identificación de la mujer con la hereje y "la bruja", centro de la persecución (Federici, 2004/2010, p. 67). La bruja era aquella que copulaba sin reproducirse, de ahí que los poderes fácticos prohibiesen "por antisociales y demoníacas" dichas prácticas; fue el momento de "transformación de la actividad sexual femenina en un trabajo al servicio de los hombres y la procreación" (Federici, 2004/2010, p. 264). Como consecuencia de dos siglos de prácticas inquisitoriales, a mediados del siglo XVI, los gobiernos europeos “imponían las penas más severas a la anticoncepción, 
el aborto y el infanticidio" (Federici, 2004/2010, p. 135). A partir del siglo XIX, la orientación "exclusiva" del cuerpo femenino hacia la reproducción fue clave, en palabras de Foucault, en el "dispositivo de sexualidad", como parte de la definición misma del sexo y vinculado al tiempo con el proceso de "histerización de la mujer" (Foucault, 1976/2007, p. 127). En este contexto decimonónico, el discurso científico también se mezclaba con el religioso, como señala Reva B. Siegel, pues al apuntar el "deber" reproductivo femenino, la comunidad médica identificaba a la mujer con la casada, hasta el punto de que en Estados Unidos, la American Medical Association (AMA), hablaba en sus recomendaciones sobre la "Providencia" y las "obligaciones del contrato marital" para denunciar el "aborto criminal", además de criticar la contracepción: "She yields to the pleasures but she shrinks from the pains and responsibilities of maternity" (Siegel, 1995, p. 48).

El poder eclesiástico ha demostrado históricamente su vigor social en el debate sobre la reproducción, circunstancia que se evidenció también en la protesta antiabortista tras la reforma legal impulsada por el Ejecutivo de Zapatero de 2010 (Bedoya, 2009). Dejando en entredicho el artículo 16.3 de la Constitución, que dicta que ninguna confesión tendrá carácter estatal, la Conferencia Episcopal exigió el posicionamiento de la ciudadanía, y además lanzó una espectacular campaña nacional con sus postulados bajo el lema Protege mi vida (La Conferencia Episcopal lanza una nueva campaña contra el aborto, 2009). A tenor de este protagonismo que la Iglesia había adquirido mediáticamente, la ilustradora Joanna Nieto aportó a Wombastic una imagen contundente: una mujer indignada disfrazada de obispo. "Igual es que hay que hablar así para que importe lo que decimos", reza la ilustración (imagen 2). Doble crítica: el silenciamiento de la mujer por el simple hecho de ser mujer, y la injerencia de la Iglesia en el intento de reforma legislativa, como aliada del Gobierno del Partido Popular.

La intervención del Estado en la regulación del cuerpo femenino es violencia de género. Impulsar una norma que "reinscribe la relación de fuerza del poder político en las instituciones y los cuerpos" (Foucault, 1976/2000, p. 29), vulnerando el derecho de la mujer a decidir, atenta contra los derechos humanos fundamentales. El discurso que defendió el Gobierno popular no solo esencializaba a la mujer en su naturaleza procreadora sino que la infantilizaba sometiéndola a tutela jurídica y médica, pues se había presentado la necesidad de que el legislador dirimiese, en palabras de Gallardón, "en aquellos supuestos de colisión entre la vida del nasciturus y la vida de la mujer” (García y Elorduy, 2013). La reflexión patriarcal que justifica esa necesidad de custodiar el cuerpo femenino se apoya en la asunción de que ella "ha aprendido la lección de ser cuerpo" condicionada por su sexo biológico, a diferencia del hombre, para el que "la corporalidad es una característica accidental" (Posada, 2015, pp. 119-120).

\section{Obligadas a reconquistar el derecho a decidir}

En el periodo de tramitación de la norma antiabortista, el Ejecutivo se encontró con la respuesta feminista en las calles, protagonizada tanto por las activistas veteranas que no podían creer que la legislación fuese a retroceder treinta años, como por las voces más jóvenes, aterradas ante la idea de convertirse en criminales al decidir sobre la conveniencia de su maternidad. La importancia del término "decidir" volvió 
al discurso social, a las pancartas, a la calle, a los medios de comunicación, y también copó buena parte de las ilustraciones de Wombastic, como la aportada por la ilustradora Nuria Tamarit (imagen 3). "Yo decido y tú te callas" apela directamente al legislador/ministro/hombre que recibe el impacto de un embarazo convertido en un ente esférico del que se desprende. Ella, empoderada al decidir libremente; él, golpeado por no respetar esa decisión. Ella desnuda; él, con traje y corbata. Tamarit subvierte el discurso patriarcal de la mujer-cuerpo dotándolo de autoridad frente a la imposición gubernamental que pretendía convertirla en criminal. De la primera posición, sumisa con la gestación, pasa a la liberación y la contestación tajante. El cuerpo es el asunto propio, y su color impregna además toda la viñeta, a excepción del tono oscuro del traje del legislador/ministro/hombre.

Figura 3. Autora: Nuria Tamarit. Fuente: Wombastic.

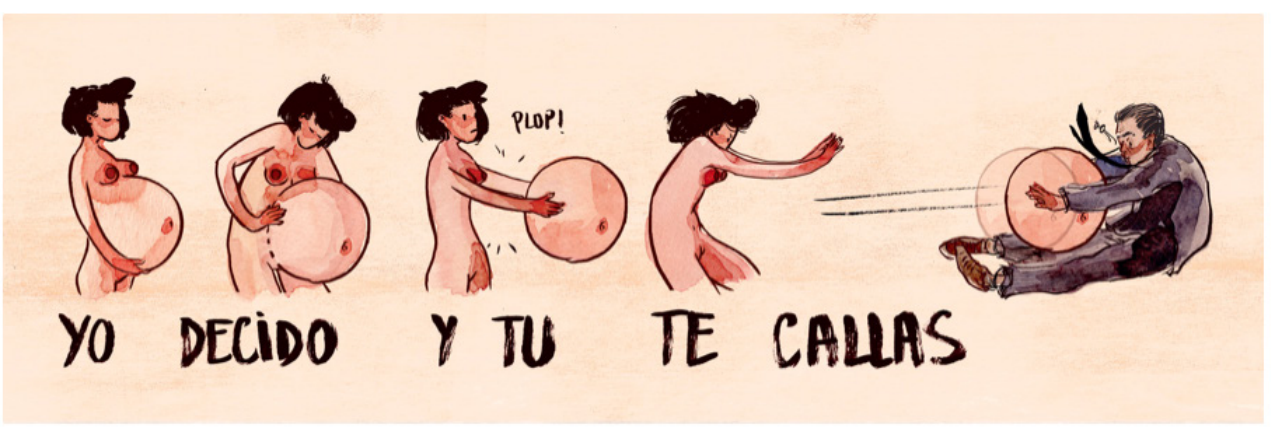

Teniendo en cuenta que "el patriarcado gravita sobre la institución de la familia, constituyendo una unidad patriarcal dentro del conjunto del patriarcado" (Millett, 1970/2017, p. 83), el argumento antiabortista alerta sobre el riesgo de destrucción de esta base social que deviene de la interrupción voluntaria del embarazo. Se pervierte así el mensaje feminista ligando, en palabras de Siegel, la lucha por la libertad de decisión con el ánimo reformador de "laws and customs of marriage and to expand women's participation in the nation's economic and political life, thus investing abortion with explosive social significance" (Siegel, 1995, p. 51). Desde las primeras victorias de la lucha feminista conseguidas en el siglo XX, el discurso patriarcal se ha preocupado por situar a las feministas como dinamitadoras del orden social y enfrentarlas, en este contexto, con las madres. Como señala Millett, "la enemistad de las mujeres entre sí" siempre ha interesado al patriarcado, que creó el primer antagonismo entre "la prostituta y la matrona", para más tarde derivarlo hacia "la mujer con profesión y el ama de casa" (Millett, 1970/2017, p. 91). Más allá de la victoria social que supuso en nuestro país la suspensión de la citada norma y la dimisión del ministro que la había defendido, la protesta incansable de cientos de mujeres durante los años en los que el Gobierno del PP elaboraba el proyecto, demostró que el antagonismo que Millett categorizaba a mediados del siglo XX, está cada vez más cerca de ser superado en pos de una sororidad que aúna a la población femenina, que ya no está dispuesta a asumir un papel subordinado en la sociedad ante los poderes legislativos y/o políticos. 
La iniciativa inédita planteada por la plataforma Wombastic se convirtió en el reflejo gráfico de esa sororidad. Hermanó no solo a la comunidad de ilustradoras participantes en un grito común ante la amenaza antiabortista de Gallardón sino que, dada la premisa de libre descarga de las imágenes, de alguna forma también hermanó a estas creadoras con todas/os aquellas/os ciudadanas/os que quisiesen utilizar sus ilustraciones y eslóganes para sumarse a la protesta contra la pretensión de incapacitar a la mujer para decidir sobre su cuerpo y, por ende, sobre su vida.

\section{Referencias}

Bedoya, Á. G. (2009, 11 de octubre). La Iglesia cree que la crisis sumará manifestantes contra el aborto. El País digital [en línea]. Recuperado de: https://elpais.com/diario/2009/10/11/ sociedad/1255212004_850215.html

Bodelón, E. (2014, noviembre). Violencia institucional y violencia de género. Anales de la Cátedra Francisco Suárez [en línea], № 48. Disponible en: http://revistaseug.ugr.es/ index.php/acfs/article/view/2783

Cué, C. E. (2014, 24 de septiembre). La ley del aborto, la historia de un fiasco. El País digital. Recuperado de: https://elpais.com/politica/2014/09/24/actualidad/1411510577_143104.html

De Miguel, A. (2015). Neoliberalismo sexual. El mito de la libre elección. Madrid: Cátedra.

Federici, S. (2010). Calibán y la bruja. Mujeres, cuerpo y acumulación originaria. (Trad. V. Hendel y L. Sebastián) [en línea]. Madrid: Traficantes de Sueños (Original en inglés, 2004). Disponible en: https://www.traficantes.net/sites/default/files/pdfs/Caliban\%20 y\%20la\%20bruja-TdS.pdf

Foucault, M. (2007). Historia de la sexualidad 1-la voluntad de saber. (Trad. U. Guiñazú). Madrid: Siglo XXI Editores (Original en francés, 1976). Recuperado de: https:// seminariolecturasfeministas.files.wordpress.com/2012/01/foucault_michel-historia_de la_sexualidad_i_la_voluntad_de_saber.pdf

Foucault, M. (2000). Defender la sociedad. Curso en el Collège de France. (A. Fontana, M. Bertani). Buenos Aires: Fondo de Cultura Económica de Argentina (Original en francés, 1976). Recuperado de: https://www.uv.mx/tipmal/files/2016/10/M-FOUCAULTDEFENDER-LA-SOCIEDAD.pdf

García, T. y Elorduy, T. (2013, 20 de diciembre). "La mujer siempre es víctima”: Gallardón presenta el anteproyecto de reforma del aborto. Diagonal digital. Disponible en: https:// www.diagonalperiodico.net/cuerpo/21213-la-mujer-siempre-es-victima-gallardonpresenta-anteproyecto-reforma-del-aborto.html

La Conferencia Episcopal lanza una nueva campaña contra el aborto (2009, 16 de marzo). Cadena SER digital. Recuperado de: http://cadenaser.com/ser/2009/03/16/ sociedad/1237173206_850215.html

Millett, K. (2017). Politica sexual. (Trad. A.M. Bravo). Madrid: Cátedra (Original en inglés, 1970).

Ministerio de Sanidad, Servicios Sociales e Igualdad (2012). Protocolo común para la actuación sanitaria ante la Violencia de Género [en línea]. Disponible en: http:// www.violenciagenero.msssi.gob.es/profesionalesInvestigacion/sanitario/docs/ PSanitarioVG2012.pdf

Nogueira, C. (2004, 8 de octubre). El Congreso aprueba por unanimidad la ley integral contra la violencia de género. El País digital. Recuperado de: https:/elpais.com/diario/2004/10/08/ sociedad/1097186401_850215.html 
Olías, L. (2014, 9 de febrero). Ilustraciones que abanderan la lucha contra la reforma del aborto. Eldiario.es. Recuperado de: https://www.eldiario.es/sociedad/Imagenesabanderan-lucha-reforma-aborto_0_225727641.html

ONU(1993). Declaración sobre la eliminación de la violencia contra la mujer [en línea]. Recuperado de: https://www.ohchr.org/SP/Professionalinterest/Pages/ViolenceAgainstWomen.aspx

ONU (1995). Informe de la IV Conferencia Mundial sobre la mujer. Recuperado de: http:// www.un.org/esa/gopher-data/conf/fwcw/off/a-20.sp

ONU (2006). Estudio a fondo sobre todas las formas de violencia contra la mujer. Recuperado de: https://undocs.org/es/A/61/122/Add.1

Posada,L.(2015,junio).Lasmujeres soncuerpo:reflexiones feministas.Investigaciones Feministas, 6. Recuperado de: https://revistas.ucm.es/index.php/INFE/article/viewFile/51382/47662

Siegel, R. (1995). Abortion As a Sex Equality Right: Its Basis in Feminist Theory. En M. Fineman y I. Karpin, Mothers in law: feminist theory and the legal regulation of motherhood. New York: Columbia University Press. Recuperado de: https://law.yale.edu/ system/files/documents/pdf/Faculty/Siegel_AbortionAsASexEqualityRight.pdf

Wombastic (2014). Recuperado de: http://wombastic.tumblr.com/

Young, I. M. (2005). On Female Body Experience. Throwing like a girl and other essays. Oxford: Oxford University Press. Recuperado de: https://biblioteca-alternativa.noblogs. org/files/2011/11/On_Female_Body_Experience__quot_Throwing_Like_a_Girl_ quot_and_Other_Essays_Studies_in_Feminist_Philosophy_.pdf 